\title{
DIREITO ISLÂMICO E DIREITO INTERNACIONAL: OS TERMOS DE UMA RELAÇÃO
}

\author{
Salem Hikmat Nasser* \\ ISLAMIC LAW AND INTERNATIONAL LAW: \\ THE TERMS OF A RELATIONSHIP
}

\section{RESUMO}

O DIREITO ISLÂMICO É POUCO CONHECIDO ENTRE NÓS, MAS A SUA RELEVÂNCIA É CRESCENTE. ESTE ARTIGO PRETENDE REMEDIAR EM PARTE A FALTA E DEMONSTRAR EM PARTE A RELEVÂNCIA, APRESENTANDO O DIREITO ISLÂMICO COMO UM SISTEMA JURÍDICO DIFERENCIADO E DISCUTINDO SUAS CARACTERÍSTICAS FUNDAMENTAIS. ESTABELECIDA ESSA BASE DE COMPREENSÃO, O TEXTO DISCUTE AS RELAÇŌES POSSÍVEIS, DE COMPLEMENTARIDADE E DE TENSÃO, ENTRE O DIREITO ISLÂMICO E OS DIREITOS NACIONAIS, ENTRE O DIREITO ISLÂMICO E O DIREITO INTERNACIONAL PRIVADO E ENTRE O DIREITO ISLÂMICO E O DIREITO INTERNACIONAL PÚBLICO. SENDO O DIREITO ISLÂMICO UM CONJUNTO NORMATIVO COM VOCAÇÃO PARA REGER TODAS AS ÁREAS DA VIDA EM SOCIEDADE E OCUPANDO UM LUGAR QUE LHE É AINDA RESERVADO POR MUITOS ESTADOS, PODE SER CHAMADO A DESEMPENHAR PAPÉIS INESPERADOS PELO JOGO DAS REGRAS DE CONFLITO DE LEIS E DE CONFLITO DE JURISDICCÕES DO DIREITO INTERNACIONAL PRIVADO, ASSIM COMO PODE AFETAR O DESENVOLVIMENTO DO DIREITO INTERNACIONAL PÚBLICO, ESPECIALMENTE NA MEDIDA EM QUE INFLUENCIA AS SUAS FONTES.

\section{PALAVRAS-CHAVE}

Sharia; Direito ISLÂMico; Direito Internacional Privado; Direito Internacional Público; Pluralismo jurídico.

\begin{abstract}
ISLAMIC LAW IS VIRTUALLY UNKNOWN AMONG US AND YET IT IS INCREASINGLY RELEVANT. THIS PAPER INTENDS TO REMEDY, IN PART, THE LACK OF FAMILIARITY AND RESPOND TO THE INCREASED IMPORTANCE. IT PRESENTS ISLAMIC LAW AS A DIFFERENTIATED LEGAL SYSTEM AND DISCUSSES THE RELATIONS IT MAY ENTERTAIN, OF COMPLEMENTARITIES AND OF TENSIONS, WITH DOMESTIC LEGAL SYSTEMS, WITH PRIVATE INTERNATIONAL LAW AND WITH PUBLIC INTERNATIONAL LAW. BECAUSE IT IS A SET OF LEGAL NORMS THAT HAS A VOCATION TO GOVERN ALL SECTORS OF LIFE IN SOCIETY, AND SINCE IT OCCUPIES SPACES THAT ARE STILL RESERVED TO IT BY MANY STATES, IT MAY BE CALLED UPON TO PERFORM UNEXPECTED ROLES, BY THE GAME OF THE RULES OF CONFLICT OF LAWS AND OF CONFLICT OF JURISDICTIONS IN PRIVATE INTERNATIONAL LAW, AS WELL AS IT MAY AFFECT THE DEVELOPMENT OF PUBLIC INTERNATIONAL LAW, SPECIALLY AS IT INFLUENCES THE LATTER'S SOURCES.
\end{abstract}

\section{KEYWORDS}

Sharia; Islamic LaW; Private International LaW;

Public International LaW; LEgal PLURALISM.

\section{INTRODUÇÃO}

A relação entre o direito islâmico e outros sistemas jurídicos (por um lado, basicamente, ordens jurídicas domésticas, estatais, de tipo ocidental, se quisermos, e, por 
outro, o direito internacional) é muitas vezes pensada em termos de compatibilidade ou incompatibilidade.

Relativamente a certas matérias de escolha, a compatibilidade de princípios (legais) islâmicos com os valores dos sistemas jurídicos, que são considerados característicos da Idade Moderna, é testada por conjuntos de questões como, por exemplo: a democracia é possível no Islã? O Islã reconhece os direitos humanos e são esses direitos compatíveis com uma concepção mais universal? O Islã reconhece ou tolera atos mais extremos de violência e justifica a violência de forma diferente?

Essas perguntas e muitas outras pressupõem a existência de um conjunto de regras ou princípios (normas, de modo geral), que, como qualquer outro conjunto de regras e princípios, pretende regular o comportamento social. Esse conjunto é genericamente referido como o direito islâmico ou como sharia.

O ponto de partida para se avaliar a relação entre o direito islâmico e o direito internacional pode ser expressado em duas questões básicas: (1) o que é o direito islâmico; e (2) onde está o direito islâmico ou onde ele existe e opera?

A primeira pergunta convida à investigação sobre se o direito islâmico pode ser considerado um sistema jurídico, sobre se esse sistema jurídico é de alguma forma comparável a outros, sobre seus traços e características, e sobre o modo como ele funciona. A segunda questão refere-se a descobrir onde o direito islâmico pode ser encontrado, em que esfera social, temporal e espacial é aplicado, e em que medida ele é aplicado.

Neste artigo, antes de lidarmos com as formas como o direito islâmico se relaciona com o direito internacional, consideraremos algumas características básicas do direito islâmico como sistema jurídico, e tentaremos uma descrição do lugar que ele ocupa na regulação dos vários aspectos da vida social, passando pelos diferentes graus de relacionamento com o direito produzido pelo Estado. ${ }^{1}$

Cumprida essa tarefa, nas seções seguintes cuidaremos das relações possíveis entre o direito islâmico e o direito internacional privado e das suas relações com o direito internacional público.

\section{DiReito ISLÂMico COMO SISTEMA JURÍDico}

O direito islâmico, ou sharia, é geralmente entendido como o conjunto das prescrições, regras e mandamentos que se aplicam a todos os aspectos da vida tanto do muçulmano, individualmente, quanto da comunidade dos fiéis. É, nesse sentido, um conjunto de normas que pretende ser completo, no sentido de abarcar toda a vida e todas as relações. Além disso, é um sistema que se define como tendo origem e natureza sagradas. ${ }^{2}$

Ele regula, primeiramente, a relação do crente com Deus (o culto ou ibada), estabelecendo os deveres da pessoa muçulmana em relação a Deus e à religião. Esses 
deveres são conhecidos como os pilares da fé: a shahada - a fórmula falada, profissão de fé, dita por muçulmanos que professam sua crença na existência de um Deus único e na escolha de Mohamad como seu Profeta; salat, ou a oração, cinco vezes por dia; hajj, a peregrinação obrigatória a Meca; siam, o jejum feito durante o mês de Ramadan; zakat, um pagamento a ser feito para o benefício dos pobres. ${ }^{3}$

A sharia não regula apenas a ibada, mas também organiza as interações sociais ou o que se chama muamalat. Nesse contexto, as regras da sharia referem-se ao estatuto pessoal dos indivíduos, às relações familiares, comerciais e econômicas. Elas também estabelecem as infrações penais e punições correspondentes. Comumente se pensa que elas organizam o sistema político no interior do Estado e pretendem regular as relações internacionais da comunidade muçulmana.

Uma terceira dimensão da sharia diz respeito ao que poderia ser chamado de moral ou ética islâmica, embora concepções restritivas da sharia possam ver tais considerações, relativas aos preceitos morais, dirigidas à consciência de cada muçulmano, regulando a generosidade, a tolerância, ou o altruísmo, como não realmente constitutivas do direito islâmico.

\section{I ORIGEM E NATUREZA DIVINAS OU SAGRADAS DO DIREITO ISLÂMICO}

As fontes das quais as regras do direito islâmico brotam e em que podem ser encontradas são o Alcorão - o livro sagrado que contém a coleção de revelações feitas pelo arcanjo Gabriel a Mohamad -, e a sunna - o conjunto de comportamentos e dizeres do Profeta, sendo ele, como se acredita, imune de erros e inspirado divinamente. É, portanto, um dogma da doutrina islâmica, a existência de uma mensagem revelada que, lado a lado com os ensinamentos, inspirados divinamente, do Profeta indicam, para os muçulmanos, os comportamentos a que estão obrigados, aqueles que são proibidos, aqueles que são recomendados e aqueles que devem ser evitados. ${ }^{4}$

O legislador não é, pelo menos em princípio, o homem, ou qualquer poder instituído ou criado por ele, mas sim Deus, que diz aos homens o que se espera deles. Esse ponto de partida, que pode ser contestado quando observamos como o direito islâmico funciona "na prática", parece estar em consonância com a essência de uma religião, expressa em seu próprio nome (Islã), que é encontrada na submissão de todas as coisas à vontade divina.

O direito deve ser identificado nas duas fontes sagradas. É preciso ou considerar que todas as regras do direito islâmico são dadas por Deus-legislador e o trabalho do ser humano é apenas descobrir quais são elas, ou acreditar que a função da atividade humana é criar as normas de acordo com essas duas fontes. Em qualquer dos casos, a questão do fundamento da ordem jurídica e do caráter obrigatório das suas normas parece resolvida. A fim de realizar uma ou outra dessas possíveis tarefas, cabe ao homem descobrir a vontade divina pela exegese do Corão, identificando os ahadith (os dizeres do Profeta e as crônicas de suas ações) ${ }^{5}$ autênticos e sua interpretação. 


\section{I.2 IJTIHAD}

O esforço que cabe ao ser humano, para tentar conhecer a vontade de Deus e descobrir ou conceber as normas jurídicas, é conhecido como ijtihad. Desse esforço surgiram os princípios do saber jurídico, usul al fiqh (a teoria do direito, se quisermos) que se referem ao direito islâmico, e o conjunto de normas, sobre cuja existência e teor há certa concordância. É claro que, a partir do mesmo esforço e dos mesmos processos também surgiram construções teóricas e normas jurídicas sobre as quais há discordância.

Usul al fiqh lidam com procedimentos, técnicas e mecanismos a serem utilizados nos processos de identificação e aplicação das normas nas situações concretas. Alguns destes são: ijma ou consenso (seja na comunidade ou entre os estudiosos do direito) sobre a existência, o conteúdo e o alcance das normas; qiyas ou raciocínio analógico, que permite que sejam aplicadas regras a situações novas mas parecidas; $a k l^{6}$ ou razão humana, na medida em que torna possível a interpretação das fontes para identificar as regras.

Usul al fiqh e os mecanismos para determinar as normas do direito islâmico estão no centro do debate moderno sobre a possibilidade, ou a falta da possibilidade, de se adaptar a sharia aos novos tempos e às novas situações sociais.

É lugar comum dizer que as portas do ijtihad foram fechadas por volta do terceiro século depois do nascimento do Islã. Assim, tanto a teoria do direito, ou usul al fiqh, quanto às normas do direito islâmico, teriam sido consolidadas para sempre nas principais escolas jurídicas, madaheb, quatro reconhecidas pelo islamismo sunita e uma escola xiita. ${ }^{7}$

Para muitos, o pré-requisito para a mise à jour do direito islâmico e sua adaptação aos tempos modernos seria a reabertura das portas do ijtihad. Para outros, tais portas nunca foram realmente fechadas e o debate sempre persistiu dentro das escolas jurídicas e entre elas. ${ }^{8}$ De qualquer modo, a questão permaneceu viva, ao que parece, sobre a possibilidade, ou a necessidade, de se adaptar a sharia, considerando as limitações hermenêuticas impostas pela natureza divina e atemporal das suas principais fontes.

Mesmo que se considere que todas as normas possíveis estão contidas no Alcorão e na sunna, e todas as situações possíveis são reguladas por tais normas, permanece o fato de que as capacidades humanas são limitadas e, portanto, lacunas e pontos cegos sempre existirão aos olhos do observador ou do aplicador do direito.

\section{I.3 Direito ISLÂmico E RegulaçÃo PARAlela}

Uma possível solução para as lacunas e para a provável inadequação de regras contidas nas principais fontes do direito islâmico ante os desafios trazidos pelas mudanças na sociedade é a aceitação da existência de regulação paralela ou a possibilidade de sua produção. Ao longo da história, as sociedades muçulmanas reconheceram outras 
formas de regulação social e produziram regulação não inspirada na sharia. No entanto, de um ponto de vista interno ao sistema jurídico, poder-se-ia indagar se o direito islâmico, além de pretender ser um sistema abrangente (ibada, mouamalat e ética), vê a si mesmo como um sistema único e exclusivo também.

Essa é uma investigação interna ao sistema jurídico islâmico no sentido de que a possibilidade de que existam normas e regras que não pertencem ao corpo de normas jurídicas da sharia, que ocorrem em paralelo ou são de outra natureza, é pensada sob a ótica do próprio direito islâmico. Esse ponto de vista interno naturalmente pressupõe a primazia do direito islâmico na regulação religiosa e legal da vida social. As questões relativas à essa investigação são tratadas pelos fuqaha, ou estudiosos da religião, e o debate é um que ocorre intra corporis. Não é, ainda, um debate sobre a relação entre o direito islâmico e outros sistemas jurídicos.

Quando as condições dessa relação - entre o direito islâmico e outros sistemas jurídicos - forem ser estabelecidas, no entanto, não haverá escapatória e será necessário considerar como o direito islâmico vê a si mesmo.

\section{I.4 Direito ISLÂMICO COMO UMA ORDEM NORMATIVA PESSOAL E COMUNITÁRIA}

O direito islâmico, uma vez que não é uma ordem normativa criada por um Estado ou por outro poder político, não está destinado a viger e ser aplicado em um território específico sobre o qual opera tal poder, pelo menos em princípio. Um Estado ou um governo só pode pretender aplicar o direito islâmico que, por definição, antecede o Estado e deve sobreviver depois dele, para e no seu território.

O direito islâmico dirige-se a cada muçulmano e, portanto, a cada ser humano, já que todos são chamados a reconhecer a revelação e a se submeterem à vontade de Deus; e se dirige à comunidade dos fiéis, onde quer que estes se encontrem. Todo muçulmano deve observar os preceitos da sharia no que diz respeito ao seu culto e ao relacionamento com Deus e com os outros. Se existir um governo que se queira guiado pelo Islã, ele deve observar e aplicar as regras do direito islâmico em suas relações com aqueles que lhe são submetidos e com outros Estados, assim como deve fazer com que aqueles que vivem sob seu domínio observem as normas da sharia. Se não houver tal governo, cada fiel deve aplicar toda e qualquer norma da sharia que depender de seu comportamento. A totalidade dos preceitos do direito islâmico, então, continuaria suspensa, mas eternamente válida, até vir o momento quando ela poderá ser aplicada.

É, portanto, uma ordem jurídica não temporal e não espacial, um chamado à espécie humana que deve criar para si os meios e as instituições que farão o direito islâmico aplicável e efetivo. É acima de tudo uma ordem jurídica que não pode ser dissociada da profissão de fé e do conjunto de crenças de um número muito significativo de pessoas que, em princípio, deve a esta ordem jurídica uma lealdade que deve superar qualquer outra ligação política ou social. 
É claro, sendo o direito islâmico fundamentalmente baseado em uma mensagem divina (sempre de acordo com seu ponto de vista interno), será capaz de governar e regular o comportamento humano e as relações sociais apenas enquanto e na medida em que a espécie humana prestar força a essa mensagem, ou porque há convicção individual e comunitária, ou porque tal mensagem é adotada por aqueles que detêm o poder. Dizer, portanto, que a sharia é dirigida a todos os muçulmanos significa essencialmente que, a partir da perspectiva do direito islâmico, Deus não conhece as fronteiras criadas pelos homens, mesmo que essas fronteiras possam afetar a forma como a espécie humana vai interpretar a vontade divina.

\section{ONDE ESTÁ O DIREITO ISLÂMICO?}

\section{RELAÇÃO COM O DIREITO INTERNO DO ESTADO}

A Idade Moderna é, dentre outras coisas, caracterizada por uma visão particular do direito. Desde que o Estado se tornou a forma universal de organização política e social, o direito é visto como algo produzido pelo Estado, controlado pelo Estado, e como um fenômeno territorialmente localizado. Direito é o sistema de regras e instituições que o Estado cria ou reconhece e devem ser aplicadas e operar dentro do seu território.

Estamos acostumados a olhar para o direito, de acordo com os principais tipos de sistemas jurídicos, ou como um conjunto de normas contidas em leis produzidas pelo legislador ou contidas em precedentes de decisões judiciais. Mas nós sempre olhamos para o Estado como o responsável final pela produção e aplicação do direito.

A primeira questão, portanto, sobre a relação entre sharia e o direito interno, é como combinar um sistema jurídico que brota, em última análise, a partir de fontes divinas com a autoridade centralizada do Estado sobre seu território.

O direito islâmico, como foi demonstrado, não é produto de legisladores nem de juízes, mas produto dos esforços de produção sábia de estudiosos do direito e da religião islâmicos. ${ }^{9}$

Inquirir sobre a extensão em que o direito islâmico é, na realidade, chamado a regular a vida dos indivíduos e das comunidades é uma investigação sobre o lugar que os vários Estados e seus sistemas jurídicos reservam para a sharia. Em outras palavras, potencialmente, a não ser que o Estado considere ser o direito islâmico todo o seu direito ou, ao contrário, negue qualquer lugar ao direito islâmico, será necessário pensar as possíveis relações entre dois sistemas jurídicos de naturezas diversas.

Estas relações podem ser de pelo menos dois tipos: ou a sharia precisa ser levada em consideração pela ordem legal do Estado, porque acompanha as pessoas ou porque se aplica a situações ou relações que interagem com o território do Estado; ou a sharia é chamada pelo próprio ordenamento jurídico para exercer nele algum papel maior ou menor. 


\section{I SHARIA DE MINORIA ${ }^{10}$}

É claro que a sharia pode ganhar importância mesmo em países cujos sistemas jurídicos não reconhecem sua capacidade de produzir ou inspirar normas jurídicas. Essa importância vem à tona quando as pessoas ou as relações governadas pela sharia interagem com o território desses Estados. Esse é o caso, por exemplo, do reconhecimento, para efeitos fiscais, das implicações decorrentes de casamentos poligâmicos de estrangeiros residentes nos Estados da Europa Ocidental. É também o caso da aceitação ou proibição de certas práticas que podem ser vistas tanto como pertencentes ao domínio das liberdades individuais ou, pelo contrário, como uma violação da noção de ordem pública.

O direito islâmico em tais casos é visto como de minoria porque suas regras acompanham o crente e regulam o culto, a obediência aos preceitos morais e as interações sociais, mas apenas dentro dos limites do que não é proibido por um sistema jurídico que não reserva para elas qualquer lugar especial de validade ou aplicabilidade.

\subsection{Direito ISlâmico COMO REGULAÇÃo PARALEla E MEIO DE SOlUÇÃo DE DisPUTAS}

O debate sobre o pluralismo jurídico é um dos mais importantes e presentes na literatura jurídica recente. A ideia de que diversos conjuntos reguladores diferentes do direito produzido pelo Estado podem compartilhar com este a função ou a organização da vida social e regular o comportamento humano tem tanto defensores quanto detratores.

E a maneira como o pluralismo jurídico é visto e definido também varia. Basicamente, pode-se olhar para o fenômeno de um ponto de vista sociológico/antropológico ou sob um ponto de vista legal, centrado no Estado. ${ }^{11}$ Em outras palavras, pode-se pensar regimes reguladores como modos concorrentes de regulação social que são independentes e externos ao direito produzido pelo Estado ou como regimes que são admitidos e autorizados pelo direito do Estado.

Independentemente do ponto de vista teórico adotado, é inegável que em qualquer sociedade o direito islâmico pode vir a funcionar como um exemplo de pluralismo jurídico, quando indivíduos e comunidades recorrem a ele como um repositório de regras que orientam seu comportamento e recorrem aos estudiosos da sharia para resolver disputas fora da estrutura do Estado.

\subsection{Direito ISLÂmico COMO FONTE Do DiReito ESTATAL}

O problema central sobre a noção de direito islâmico ou sharia como fonte de direito estatal - e muitas ordens jurídicas domésticas expressamente lhe reconhecem esse status - consiste em articular a possibilidade de um sistema jurídico ser a fonte para outro sistema, quando ambos se constituem e veem a si mesmos como uma totalidade - mesmo que haja discussões e incertezas sobre o funcionamento e os conteúdos normativos, como acontece, aliás, com qualquer sistema legal -, mas são especialmente relevantes para um deles. 
O direito islâmico pode ser uma ou a fonte de um sistema jurídico nacional quando é em si todo o direito que é válido e diretamente aplicável nesse Estado. Pode ser considerado uma fonte quando o Estado se propõe a legislar, criando normas cujo conteúdo coincide com os preceitos da sharia, que, neste caso, não seria diretamente aplicável ou válida como direito islâmico, a não ser pela mão do direito estatal. Pode-se considerar o direito islâmico como sendo uma fonte também quando ele serve de inspiração para o sistema jurídico do Estado de modo que as regras do último estão em conformidade com o "espírito" das normas da sharia.

Quando se discute as fontes do direito, é usual falar-se de fontes formais e materiais. Estas são pensadas como o que inspira e justifica o conteúdo normativo e as primeiras constituiriam os instrumentos, técnicas ou mecanismos que permitem a criação, emergência e identificação das normas válidas. Como se vê, o direito islâmico pode ser entendido como uma fonte em qualquer um dos sentidos.

O que não pode ser ignorado, no entanto, é que, não importando quão relevante o lugar dado por sistemas jurídicos ao direito islâmico como uma fonte, a sharia perde a primazia que, na sua própria perspectiva, deveria ter. Ela é então dependente do poder do Estado e do seu direito, que escolhe entre as regras do direito islâmico aquelas consideradas adequadas para regular as relações sociais no território do Estado, e interpreta as normas da sharia de acordo com os princípios, técnicas e instituições que não são os do próprio direito islâmico.

O direito islâmico, depois de sofrer uma primeira "descida à terra", quando a vontade divina é interpretada pelo elemento humano, sofre uma segunda queda uma vez que é reduzido aos espaços reservados a ele pela vontade legisladora do Estado. Quando fonte de direito estatal, a sharia é mais marcadamente o produto da ação humana, já que é fragmentada e instrumentalizada.

Vale a pena indagar, então, sobre as razões que levam à insistência na combinação de dois sistemas jurídicos que são tão distintos e à insistência em fazê-los conviver.

Todo direito, quer seja secular, quer pretenda de qualquer forma ser decorrente da vontade de Deus, deve ser o resultado de uma combinação de necessidades sociais identificadas com os valores existentes, e isso vai depender de jogos de poder e da distribuição de poder no espaço social. Nisso reside a única resposta genérica possível à pergunta sobre o porque de a sharia ainda resistir no núcleo dos sistemas jurídicos de muitos Estados.

\section{Direito islâmico e Direito internacional PRIVAdo}

Direito internacional privado é, como se sabe, aquela parte dos sistemas jurídicos nacionais que se ocupa em responder a algumas perguntas fundamentais que surgem quando o sistema deve enfrentar situações conectadas a mais de um ordenamento jurídico, o nacional e um ou mais estrangeiro. As duas perguntas mais importantes 
dizem respeito ao tribunal a que a situação será levada, o que implica a determinação da sua competência internacional, e à lei a ser aplicada para responder às perguntas jurídicas levantadas. Essas perguntas são conhecidas pelas expressões "conflito de jurisdições" e "conflito de leis". As situações conectadas a mais de um ordenamento devem ser de natureza privada, ou seja, relativas ao estatuto pessoal, aos direitos de família, às relações contratuais ou à responsabilidade civil.

Cada direito nacional contém regras que dão os critérios da competência internacional dos tribunais estatais; as regras indicam qual é a conexão necessária com o ordenamento jurídico para que os tribunais sejam exclusiva ou concorrentemente competentes, por exemplo, como no caso brasileiro, o domicílio do réu, o lugar de constituição da obrigação ou de seu cumprimento, etc.

Também, cada ordenamento estabelece os elementos de conexão, domicílio, nacionalidade, lugar de celebração, lugar de cumprimento, etc., que indicarão as normas substantivas a serem aplicadas ao caso, aquelas do próprio ordenamento do juiz ou as de um ordenamento estrangeiro.

Isto quer dizer, primeiro, que mais de um tribunal, de dois ou mais países, podem se considerar competentes para resolver uma mesma questão e, em seguida, que o tribunal que se considerar competente terá que decidir se aplica seu próprio direito ou se aplica um direito que não é o seu, um direito estrangeiro.

A possibilidade de mais de um judiciário ser provocado e se considerar competente abre, é claro, as portas ao risco de decisões paralelas, que podem aplicar ou não normas jurídicas pertencentes a ordenamentos diversos - por usarem critérios de conexão diferentes - e chegar a conclusões que podem ser divergentes.

Ainda que não aconteça esse paralelismo de procedimentos, a decisão a que chegar um judiciário nacional sobre uma situação conectada a mais de um ordenamento pode necessitar que lhe sejam conferidos efeitos em outro ordenamento que não aquele em que foi produzida. Cada sistema jurídico nacional tem também as suas próprias regras para o reconhecimento e execução de decisões oriundas de outros sistemas.

Porque as incertezas sobre a competência e as incertezas sobre o direito que um ou mais judiciários aplicarão trazem insegurança excessiva quanto às soluções finais, que se pode esperar para as situações de natureza privada conectadas a mais de um ordenamento, e também porque há incerteza sobre os efeitos que pode ou não ter a decisão de um judiciário no ordenamento jurídico estrangeiro, tenta-se há muito operar alguma medida de harmonização do direito internacional privado.

Esse esforço se faz normalmente por meio de instrumentos de direito internacional público, no mais das vezes tratados, que têm por objeto ou a harmonização dos elementos de conexão usados para determinar a competência ou a lei aplicável, ou a harmonização dos critérios para o reconhecimento de decisões estrangeiras, ou a harmonização do próprio direito material, substantivo, aplicável às situações privadas. 
Pois bem, como vimos, o direito islâmico constitui ou inspira alguma parte do direito das relações privadas em vários países. Em alguns, se restringe ao estatuto pessoal capacidade, personalidade, direito de família - e, em outros, toca também as relações contratuais ou de responsabilidade.

Num mundo em que as distâncias vão se encurtando e em que se multiplicam as relações que atravessam as fronteiras conectam-se assim, naturalmente, a mais de um ordenamento jurídico, e, na medida em que essas relações alcançam também os países do chamado mundo muçulmano, aumentam as probabilidades de que situações de natureza privada sejam levadas aos tribunais desses países, e aumentam as probabilidades de que, levadas a outros tribunais, estes se vejam confrontados com a aplicação de um direito decorrente da ou influenciado pela sharia.

Quando questões atinentes ao estatuto pessoal ou ao direito de família são levadas a tribunais islâmicos, é de se esperar que estes apliquem a sharia, já que essa é a extensão de sua competência. Quando as mesmas questões são levadas a tribunais estatais encarregados de aplicar, também, mas não necessariamente, o direito islâmico, o mais natural é que se funde a decisão na sharia quando se verificar o pertencimento de uma ou de ambas as partes à confissão islâmica.

De modo similar, os tribunais islâmicos aplicarão sempre o direito islâmico aos contratos e outras relações privadas patrimoniais, caso se considerem competentes para conhecer a questão que lhes é apresentada. Os demais tribunais considerarão se devem aplicar o direito nacional, se, dentro deste, é aplicável o direito islâmico, ou se devem aplicar o direito estrangeiro.

Questões igualmente complexas são o tema mais comum de preocupação para os tribunais seculares, ocidentais, se quisermos: (1) se aplicar ou afastar a aplicação, como aplicar, como fazer a prova e como interpretar o direito islâmico quando as regras de conflito de lei indicarem a sua aplicação ou quando as partes de um contrato tenham assim desejado; e (2) se reconhecer ou não efeitos a decisões fundadas em direito islâmico e oriundas de outros tribunais.

No que respeita ao estatuto pessoal e ao direito de família, o direito islâmico tem regras que são as suas sobre o início e o fim da personalidade, sobre a extensão da capacidade jurídica de homens e mulheres, sobre matrimônio, sobre divórcio, sobre regime matrimonial (na verdade, sobre dote), sobre sucessão, filiação, etc.

As regras de conflito de um sistema jurídico qualquer levarão à possível aplicação do direito islâmico: ou porque indicaram como aplicável o direito material de um sistema jurídico em que o direito material é constituído pela sharia ou em grande medida inspirado por ela; ou porque indicaram como aplicáveis as normas substantivas de um sistema jurídico que determina a aplicação aos muçulmanos das normas da sharia. A segunda situação é mais comum: a regra de conflito indica, por exemplo, a aplicação do direito libanês que, por sua vez, aplica a cada pessoa e a cada grupo confessional, em matéria de direito de família, sucessões e estatuto pessoal, o seu direito de origem religiosa. 
Quando essas situações se apresentam ao juiz brasileiro, por exemplo, o primeiro desafio é descobrir o conteúdo normativo do direito islâmico em relação à questão ou questões jurídicas que tem diante de si. Esse desafio inclui as tarefas de fazer a prova dos conteúdos normativos, de pacificar controvérsias sobre esses conteúdos e suas interpretações e, claro, de estabelecer as fontes de onde devem ser tirados esses conteúdos. Esses desafios estão sempre presentes quando um juiz se vê obrigado a aplicar um direito que não é o seu, um direito estrangeiro, mas, à luz do que foi dito sobre o direito islâmico, sobre o caráter divino de suas fontes principais, sobre as especificidades de sua teoria geral, sobre a pluralidade de escolas jurídicas que divergem tanto sobre a teoria geral quanto sobre os conteúdos normativos; percebe-se que o desafio ganha cores especiais.

De um modo ou de outro, no entanto, esse desafio é superado, ainda que por vezes o seja à custa de reduções e erros, e, nesse momento, surge o próximo desafio que coloca o juiz diante da escolha entre aceitar as soluções normativas oferecidas pelo direito islâmico ou rejeitá-las. Deverá decidir, por exemplo, se aplica o direito islâmico e reconhece como válido um segundo casamento de um homem muçulmano que continua casado com uma primeira esposa; se presta validade ao divórcio decorrente da vontade unilateral do homem; se aceita o instituto do dote previsto pela sharia, como dever do homem e direito da mulher, como equivalente a um acordo relativo ao regime matrimonial, etc.

Normalmente, os sistemas jurídicos elencam as razões que autorizam um juiz a afastar a aplicação da lei estrangeira ou o reconhecimento de sentenças estrangeiras, como, ofensa à ordem pública, ofensa à soberania nacional, fraude à lei, a inexistência no sistema pátrio de instituto idêntico ou similar.

Quando se trata de aplicar o direito islâmico em situações como as imaginadas, pode haver uma tendência a multiplicar o recurso a essas justificativas para afastar a aplicação da sharia e voltar à posição de conforto de onde se recorre ao direito doméstico, nacional. Muitas vezes, poderá ser feita referência inclusive a uma percebida incompatibilidade das soluções do direito islâmico com os direitos fundamentais protegidos constitucionalmente e em instrumentos internacionais.

Resta o fato, no entanto, de que a recusa da aplicação do direito islâmico ou do reconhecimento de sentenças que o apliquem dará lugar sempre a instâncias concretas do problema genérico da falta de harmonização do direito privado: situações reais que têm status jurídico diferente em diversos sistemas - um casamento que é válido em um e nulo em outro, por exemplo - e um potencial de consequências deletérias - para o direito a alimentos da segunda esposa ou para a filiação de crianças nascidas de matrimônio considerado nulo, por exemplo.

Coisas muito parecidas podem ser ditas, com respeito aos desafios de identificação, aplicação ou afastamento do direito islâmico, quando se trata de fazer o exercício em situações de cunho patrimonial ou comercial, responsabilidade civil, contratos. 
Em relação aos contratos, ao comércio, no entanto, algumas considerações ganham coloração específica porque, a um tempo, se afastam um pouco do tema dos direitos fundamentais e daquele da ordem pública, tão afetos os dois aos assuntos do estatuto pessoal e do direito de família, e se aproximam da liberdade e da autonomia da vontade.

Ainda que, em relação aos contratos, do ponto de vista do direito internacional privado, a pergunta fundamental continue a ser a mesma - qual é o direito, qual é o sistema jurídico, qual é o direito substantivo mais apropriado para uma determinada situação conectada a mais de um ordenamento? - e ainda que vários sistemas, inclusive o brasileiro, tendam a ignorar pelo menos em parte a vontade dos contratantes, o fato é que há uma tendência geral a considerar que o melhor direito é aquele que as partes quiserem ver aplicado.

E é fato que muitas partes, em muitos contratos, em número provavelmente crescente, querem em alguma medida ver aplicado o direito islâmico. Elas podem fazer isso de três maneiras, essencialmente: escolhendo como foro competente aquele de um país em que o direito sofre algum grau de influência do direito islâmico e tendente a aplicá-lo, é claro; escolhendo como direito aplicável a própria sharia ou um direito nacional que dela decorra ou nela se inspire; incorporando aos termos do contrato princípios, normas, regras tirados do direito islâmico.

Um exemplo pode jogar luz sobre alguns dos problemas que podem surgir e sobre as dificuldades para lidar com eles. Num caso decidido nos tribunais ingleses, ${ }^{12}$ os juízes tiveram que lidar com uma referência feita aos "princípios da gloriosa sharia" na cláusula de lei aplicável a um contrato entre um banco do Bahrein, de um lado, e os tomadores de alguns empréstimos e seus garantidores, todos de Bangladesh.

O banco não estava obrigado pela sua regulação nacional a aplicar o direito islâmico às suas operações, mas, de modo voluntário, pretendia adequar as suas atividades à sharia. Para isso, contava com um conselho que, por amostragem, verificava a aderência das operações aos preceitos do islamic banking.

Porque o banco se impunha esse curso de ação, não poderia cobrar juros sobre os empréstimos que concedera às empresas de Bangladesh. Como, ostensivamente, os fundos estavam sendo desembolsados para a compra de mercadorias, pelos contratos originais, o banco faria a compra e revenderia aos tomadores do crédito, tendo seus ganhos garantidos pela diferença de preço. Para fazer a compra, no entanto, o banco nomeava uma das empresas tomadoras como seu agente. Esse tipo de contrato, nomeado murabaha, significa que, em vez de cobrar juros, o banco participa do risco da operação comercial e da própria atividade e dela tira um lucro.

Como os devedores deixaram de cumprir em parte o plano de pagamentos ao banco, após renegociação, outros contratos foram firmados em que alguns ativos dos devedores eram transmitidos ao banco, mas continuariam a ser usados pelas empresas contra o pagamento de montantes que somavam o principal devido ao lucro do 
banco. Esses contratos, chamados de ijara, são algo similar à locação. Aqui, portanto, em princípio, também se afastava a usura, a cobrança de juros.

Todos os contratos continham uma escolha de foro competente, os tribunais ingleses, e apenas os primeiros continham uma cláusula de lei aplicável que comandava a aplicação da "lei inglesa, submetida aos princípios da gloriosa sharia". ${ }^{13}$

Com base nessa cláusula, os devedores, inadimplentes novamente, argumentaram que todos os contratos eram, na verdade, meros disfarces para empréstimos com cobrança de juros e, por isso, contrários à sharia, que, de acordo com o contrato, seria o direito aplicável. Pedem a nulidade dos contratos e, portanto, a ineficácia da cobrança com base neles.

O tribunal inglês considerou as questões supramencionadas sobre a prova, o conteúdo, a interpretação e as várias escolas do direito islâmico; constatou as dificuldades, mas não resolveu-as. O que lhe proporcionou a porta para escapar dessas questões espinhosas foi a leitura que fizeram da cláusula de direito aplicável. Como a regra de conflito inglesa para a determinação da lei aplicável está contida numa convenção europeia sobre a matéria, a Convenção de Roma, e como ela determina que a lei aplicável deve ser uma só e precisa ser uma lei nacional, a única interpretação aceitável para a cláusula era que o direito inglês havia sido escolhido e a referência à sharia deveria ser desconsiderada.

O tribunal foi provocado igualmente a considerar se a referência feita à sharia não deveria ser entendida como a incorporação, no contrato, de seus princípios, especialmente aquele que proíbe a usura. Aqui também a resposta foi negativa.

O exemplo, além de ilustrar alguns dos problemas a que se fazia menção antes, traz uma das duas mais marcantes peculiaridades do direito islâmico aplicável aos negócios, a proibição da usura. A outra é a restrição aos contratos de risco excessivo, o que, por um lado, impõe desafios, por exemplo, para a indústria de seguros e, por outro, parece ter servido de proteção contra as consequências negativas sobre os mercados financeiros da alavancagem excessiva dos derivativos.

Finalmente, cabe uma menção rápida ao fato de que várias das questões que acabam de ser discutidas com relação ao mecanismo do direito internacional privado aplicado às relações contratuais se colocam de modo similar quando as controvérsias são levadas à arbitragem ao invés dos judiciários nacionais, estatais. Nesses casos, talvez pudesse ser aplicada maior flexibilidade à exigência de ser o direito aplicável um direito nacional. Além disso, abrir-se-iam, mais evidentemente, as portas para a investigação das relações possíveis entre o direito islâmico e a lex mercatoria.

\section{Direito ISLÂmico E DiReito INTERNACIONAL PÚblico}

Dificilmente há alguma necessidade de definir neste artigo direito internacional público e de discutir as suas características como um sistema jurídico. Basta dizer que 
ele é geralmente visto como o conjunto de regras e instituições que regulam o comportamento entre os Estados. Suas normas e instituições resultam, essencialmente, dos tratados celebrados pelos Estados e dos costumes constituídos por uma combinação de prática estatal e de opinio juris. ${ }^{14}$

O direito internacional vê a si mesmo como um sistema jurídico organizado em torno do princípio da igualdade soberana dos Estados, o qual opera em uma sociedade horizontal de Estados em que não há nenhuma autoridade central responsável pela criação ou pela aplicação das normas. ${ }^{15}$

Esse sistema jurídico lida com todas as questões que surgem como importantes - e necessitando de regulação por normas jurídicas - para os Estados. Tal relevância dos temas objeto de regulação jurídica será expressada na decisão voluntária dos Estados de celebrar tratados relativos a eles ou no desenvolvimento da prática dos Estados em um campo específico, dando lugar ao surgimento de normas costumeiras. É assim que o direito internacional passa a conter normas e instituições que tratam de temas como a paz e a segurança, direitos humanos, meio ambiente, direito do mar, a diplomacia, etc.

De forma muito esquemática, pode-se dizer que o direito internacional continua a lidar com questões que dizem respeito, exclusivamente ou de forma mais próxima, à coexistência e à cooperação entre os Estados, mas tem cada vez mais regulado campos que eram tradicionalmente pensados como de competência exclusiva da regulamentação e do direito internos, estatais.

Quando tentamos perceber a possível relação entre o direito islâmico e o direito internacional, essa distinção básica entre os momentos em que o direito internacional regula as relações entre os Estados propriamente e aqueles em que essa regulação afeta outras relações ao modificar ou influenciar os direitos internos será útil. Isto porque, como vimos, o direito islâmico contém regras que se relacionam com todos os aspectos da vida, incluindo, por exemplo, as relações entre particulares, que são reguladas pelo direito nacional, e as relações internacionais do Estado ou da nação islâmicos.

É incontroverso, ainda que o tema seja pouco estudado, que o direito islâmico tal como aparece a partir das fontes básicas e do trabalho dos fuqaha - contém disposições relativas a relações internacionais, tratados e diplomacia, direito da guerra e da paz, direito humanitário, direito do mar, relações econômicas internacionais e direitos humanos. Esse direito internacional islâmico é normalmente conhecido por Syiar. ${ }^{16}$

Pelo menos dois estudiosos muçulmanos clássicos, Abd Alrahman Alouzay (707774 AD), e Mohammad Alhassan Alshaibany (750-804 AD), lidaram em profundidade com essas questões e com o tratamento que a elas é reservado pelo direito islâmico. ${ }^{17}$ O que continua por ser visto é se o direito internacional, como o conhecemos hoje, sofreu alguma influência desses pensamentos enquanto se desenvolveu e se ainda hoje é possível algum tipo de coabitação ou de influência mútua. 
Não resta dúvida de que o direito internacional público, tal como o conhecemos, é de origem e inspiração europeias. Ainda que inclua conteúdos coincidentes com aqueles do syiar, permanece o fato de que como sistema jurídico, o direito internacional público apresenta diferenças estruturais importantes em comparação com o direito islâmico.

David Westbrook aponta o que chama de dificuldades cognitivas que opõem os dois sistemas. Para começar, diz, o direito islâmico está focado no indivíduo e não reconhece instituições intermediando a relação entre o fiel, de um lado, e Deus e seu direito, do outro. Já o direito internacional público está construído em torno de instituições e reconhece na mais importante delas, o Estado, a unidade básica do sistema. Além disso, enquanto o direito internacional, de feitura ocidental e liberal, trabalha com a ideia de um sistema coerente de regras prospectivas decorrentes da vontade soberana dos Estados, o direito islâmico está fundado na única soberania possível, aquela de Deus, cuja vontade os homens não podem conhecer inteiramente. Por essa razão, o direito islâmico e sua justiça se realizariam não no sistema de normas, mas no conjunto de decisões individuais em que se tenta obedecer à vontade divina. ${ }^{18}$

Essa incompatibilidade não é assim vista por todos, mas os argumentos pela complementaridade não costumam ser dirigidos às características sistêmicas, mas aos conteúdos. Nesse sentido, falar-se-á ou de coincidência de conteúdos entre os dois sistemas, ou de incorporação de conteúdos do direito islâmico no direito internacional por via das fontes desse último.

O direito islâmico pode interagir com as fontes do direito internacional de vários modos. Apenas um quadro geral dessas interações pode ser esboçado aqui.

Como foi dito, o direito islâmico contém disposições relativas ao direito dos tratados - que, a julgar pelos trabalhos citados de Alouzay e Alshaibany, são muito abrangentes. Naturalmente, essas disposições, ou seus equivalentes, ou são incorporadas à Convenção de Viena sobre o Direito dos Tratados, ou operam como regras consuetudinárias que podem ser válidas e aplicáveis entre certos Estados.

Em relação ao direito costumeiro internacional, duas situações principais podem ser concebidas: o comportamento dos Estados que pretendem aplicar o direito islâmico para as suas relações internacionais pode ser parte da prática generalizada e da opinio juris que vão contribuir para o surgimento ou identificação de normas costumeiras; o mesmo comportamento pode constituir direito consuetudinário regional ou não geral.

Princípios do direito islâmico, ou seja, princípios contidos nos direitos nacionais em que a Sharia ocupa algum lugar, podem também ser encarados como princípios gerais de direito, no sentido do artigo 38 do Estatuto da Corte Internacional de Justiça, e virem a ser aplicados por esse ou por outros tribunais internacionais quando não se puder encontrar soluções para as questões jurídicas nos tratados ou nos costumes internacionais. 
Saber se os conteúdos normativos do direito internacional advêm, são influenciados, coincidem ou não guardam qualquer relação com os do direito islâmico tem, na verdade, menor interesse prático do que saber se a esse direito se tem reservado algum papel na identificação e aplicação do direito internacional a casos concretos.

Essa investigação é mais fácil de fazer olhando-se para as decisões da Corte Internacional de Justiça. Em trabalho que faz o senso das menções ao direito islâmico nessa jurisprudência, Clark Lombardi ${ }^{19}$ mostra um quadro em que as poucas referências ao direito islâmico têm, ao final, pouco peso nas decisões e, em geral, são feitas com o propósito de legitimar perante os países muçulmanos as decisões ou, quando não são feitas pela Corte, a sua falta é notada por um ou outro juiz, em opiniões concordantes ou dissidentes, e lamentada também com base em preocupações de legitimidade.

Finalmente, como dito antes, o direito internacional tem uma relação estreita com os sistemas jurídicos nacionais e tende a influenciá-los cada vez mais. Na medida em que o direito islâmico pode ser reconhecido como parte de uma ordem jurídica interna, ou podendo, em alguns casos, constituir ele mesmo o sistema jurídico, acontecerão atritos entre o direito islâmico - como parte do direito interno e o direito internacional, que tende a penetrar todos os aspectos da vida doméstica.

Tais atritos podem ocorrer, por exemplo, entre os modelos de Estado e de direito (Estado de Direito) desenvolvidos pelo direito internacional e as concepções de Estado e de direito contidas no direito islâmico. Podem ocorrer também entre as normas internacionais sobre direitos humanos - com seus valores subjacentes - e o direito de família islâmico.

: ARTIGO APROVADO (02/12/2012) : RECEBIDO EM 20/03/2012

NOTAS

* Sou muito grato a Adriane Sanctis de Brito pelo precioso auxílio na pesquisa e na organização do texto.

1 A primeira parte deste artigo, descritiva, por assim dizer, do direito islâmico ou da sharia, coincide em grande parte com um texto anterior meu (NASSER, Salem H. Seria a sharia a única fonte do direito nos países árabes?). A repetição se justifica, no entanto, à luz do fato de que o direito islâmico é pouco conhecido entre nós e a discussão de suas relações com outros sistemas jurídicos seria incompreensível sem que se fizessem notar as características básicas do sistema.

2 Ver SOURDEL, Dominique and Janine. Dictionnaire historique de l'Islam, PUF: Paris, 1996, p. 503 e ss. 
3 Não há discordância entre as principais linhas do Islã, a sunita e a xiita, no que se refere a esses pilares. Muçulmanos xiitas, entretanto, acreditam na existência de imãs (líderes religiosos, mas também detentores de poder secular), únicos corretamente orientados e destinados a reger a Umma ou a nação islâmica.

4 A classificação das regras da sharia em graus de obrigatoriedade é usual; Tareq OUBROU, por exemplo, fala de sete graus: obrigação, recomendação, permissão, não desejável, proibição, e, para contratos, validade ou nulidade; em La sharî’a de minorité. In FRÉGOSI, Franck (org.). Lectures contemporaines du droit islamique, PUS: Strasbourg:, 2004, p. 211.

5 As técnicas utilizadas para identificar os ahadith autênticos são uma parte dos usûl al fiqh. Também neste campo da teoria do direito podem ser encontradas diferenças entre as escolas sunitas e xiita.

6 Sobre os usûl al fiqh, veja, p.ex., HALLAQ, Wael, A History of Islamic Legal Theories (Cambridge University Press: Cambridge, 1999), ainda que ele restrinja o estudo às escolas do ramo sunita. Também é útil consultar as diferentes expressões em SOURDEL, veja nota 3.

7 Estas escolas são a Maleky, a Hanafy, a Chafey e a Hanbaly, e se originam a partir dos nomes de estudiosos usûl al fiqh dos primeiros séculos da história islâmica. Além dessas escolas, é necessário mencionar aquela inspirada pelo Imã Jaafar AlSadiq, que é seguida por muçulmanos xiitas, especialmente os xiitas duodecimais (que acreditam na existência de doze Imãs) e que tem respostas divergentes sobre vários campos do direito islâmico, incluindo no que diz respeito ao fechamento das portas do ijtihad.

8 Veja, a esse respeito, a crítica direcionada ao fechamento das portas do ijtihad de Eric CHAUMONT em Quelques réflexions sur l'actualité de la question de l'ijtihâd, in FRÉGOSI, Franck, org., Lectures contemporaines du droit islamique (Estrasburgo: PUS, 2004), p. 71-79.

9 Veja JACKSON, Sherman A., Legal Pluralism Between Islam and the Nation-State: Romantic Medievalism or Pragmatic Modernity?, Fordham Int'l Law Journal, n. 158, p. 166-167, 2006-2007.

10 A expressão é inspirada na usada por OUBROU (veja nota 4), sharia de miorité, sem necessariamente reproduzir sua teoria ou pensamento.

11 JACKSON, nota 9 supra.

12 England and Wales Court of Appeal (Civil Division) Decisions $>>$ Beximco Pharmaceuticals Ltd \& Ors vs. Shamil Bank of Bahrain EC [2004] EWCA Civ 19 (28 January 2004). Disponível em: <http://www.bailii.org/ew/ cases/EWCA/Civ/2004/19.html>. Cite as: [2004] EWCA Civ 19, [2004] 1 WLR 1784.

13 Idem.

14 Ou seja, a convicção de que determinadas condutas são juridicamente devidas, obrigatórias, permitidas ou proibidas.

15 É claro que algumas instituições, alguns órgãos criados pelos Estados são por eles dotados de capacidade para produzir normas e velar pela sua aplicação. O que não existe é um poder central, acima dos Estados, com o poder genérico de realizar essas funções.

16 Veja AL MAJZOUB, Mohammad, Al Kanoun Al Doualy Al AM (em árabe), 5. ed. (Almanshurat Alhalabi Alhukoukyiat: Beirut, 2004).

17 Ibid.

18 Veja WESTBROOK, David A., Islamic International Law and Public International Law: separate Expressions of World Order, Virginia Journal of International Law, v. 33, p. 819-897, 1993.

19 Veja LOMBARDI, Clark B., Islamic Law in the Jurisprudence of the International Court of Justice: An Analysis. Chicago journal of International Law, v. 85, p. 85-118, 2007-2008. 


\section{REFERÊNCIAS BIBLIOGRÁFICAS}

AHMAD, Ali. The Role of Islamic law in the Contemporary World Order. Journal of Islamic Law and Culture, v. 6, p. 157-172, 2001.

AL MAJZOUB, Mohammad. Al Kanoun Al Doualy Al AM (em árabe). 5. ed. Almanshurat Alhalabi Alhukoukyiat: Beirut, 2004.

BADR, Gamal Moursi. Islamic Law: Its Relation to Other Legal Systems. The American Journal of Comparative Law, v. 26, n. 2, p. 187-198, 1978.

BRANSON, David J.; WALlACE JR.; Richard E. Wallace. Choosing the Substantive Law to Apply in International Commercial Arbitration. Virginia Journal of International Law, v. 27, p. 1-64, 1986-1987. CHAUMONT, Eric. Quelques réflexions sur l'actualité de la question de l'ijtihâd. In: Franck Frégosi. (Org.) Lectures contemporaines du droit islamique. Estrasburgo: PUS, 2004.

HALLAQ, Wael. A History of Islamic Legal Theories. Cambridge University Press: Cambridge, 1999.

INTERNATIONAL LAW ASSOCIATION CONFERENCE. Islamic Law \& International Law, The Hague Conference. Draft Report. Hague: International Law association, 2010.

JACKSON, Sherman A. Legal Pluralism Between Islam and the Nation-State: Romantic Medievalism or Pragmatic Modernity? Fordham Int'l Law Journal, n. 158, 2006-2007.

KHADDURI, Majid. Nature and Sources of Islamic Law. GeorgeWashington Law Review, n. 22, p. 3-23, 1953-1954. KHAN, Ali. The Responding of the Islamic Code: The Second Era of Ijtihad. University of St. Thomas Law Journal, v. 1, p. 341-385, 2003.

KHAN, Almas. The Interaction between Shariah and International Law in Arbitration. Chicago Journal of International Law, v. 6, p. 791-802, 2005-2006.

KUTTY, Faisal M. The Shari'a Factor in International Commercial Arbitration. Bepress Legal Series, Paper 875, p. 1-78, 2005.

LOMBARDI, Clark B. Islamic Law in the Jurisprudence of the International Court of Justice: An Analysis. Chicago journal of International Law, v. 85, p. 85-118, 2007-2008.

MAKDISI, John. Islamic Law Bibliography. Law Library Journal, v. 78, p. 103-187, 1986.

MASUD, Muhammad Khalid. Islamic Law and Muslim Minorities. International Institute for the Study of Islam in the Modern World Newsletter, n. 11, p. 17, 2002.

MOHAMMED, Noor. Principles of Islamic Contract Law. Journal of Law and Religion, vol. 6, p. 115-130, 1988. NASSER, Salem H. Seria a sharia a única fonte do direito nos países árabes? In: H. V. Araújo. (Org.) Diálogo América do Sul - Países Árabes. Brasília: Funagipri, 2005.

OUBROU, Tareq. La sharî’a de minorité. In: Franck Frégosi. (Org.) Lectures contemporaines du droit islamique. Estrasburgo: PUS, 2004, p. 211.

RAYER, Susan E. The Theory of Contracts in Islamic Law: A Comparative Analysis with Particular Reference to the Modern Legislation in Kuwait, Bahrain and the United Arab Emirates. 1. ed. Londres: Graham\&Trotman, 1991. REHMAN, Javaid. The Sharia, Islamic Family Laws and International Human Rights Law: Examining the Theory and Practice of Polygamy and Talaq. International Journal of Law, Policy and the Family, n. 21, p. 108$127,2007$.

SALEH, Nabil A. Unlawful Gain and Legitimate Profit in Islamic Law: Riba, Gharar, and Islamic Banking. 2. ed. London, 1992.

SLOANE, Peter D. The Status of Islamic Law in the Modern Commercial World. International Lawyer, n. 22, p. 743-766, 1988 .

SOURDEL, Dominique; SOURDEL-THOMINE, Janine. Dictionnaire historique de l'Islam. Paris: PUF, 1996. TAHER, Abul. Revealed: UK's first official sharia courts. The Sunday Times, 14 Set. 2008, Londres. Disponível em: $<$ http:/ / www.timesplus.co.uk/tto/news/ ?login=false\&url=http $\% 3 \mathrm{~A} \% 2 \mathrm{~F} \% 2 \mathrm{Fwww}$. thetimes.co.uk $\% 2 \mathrm{Ftto} \% 2 \mathrm{Ffa}$ ith\%2F\%3Fprint\%3Dyes\%26randnum>. Acesso em: 8 mar. 2012.

TIBI, Bassam. Islamic Law/Shari'a, Human Rights, Universal Morality and International Relations. Human Rights Quarterly, v. 16, p. 277-299, 1994.

WEISS, Bernard. Interpretation in islamic Law: the Theory of IJTIHAD. The American Journal of Comparative Law, v. 26, p. 199-212, 1977-1978.

WESTBROOK, David A. Islamic International Law and Public International Law: separate Expressions of World Order. Virginia Journal of International Law, v. 33, p. 819-897, 1993. 
Salem Hikmat Nasser

Rua Rocha, n. $233-8^{\circ}$ andar Bela Vista - 01330-000 São Paulo - SP - Brasil salem.nasserafgv.br
Professor na Faculdade de Direito de São Paulo da Fundação Getulio Vargas (DIREITo GV) 